\title{
TEXTOS INÉDITOS DE FRIEDRICH SELLOW. 2 - NOTAS SOBRE COLHEITA E PREPARO DA ERVA-MATE ${ }^{1}$
}

\author{
JOSÉ NEWTON CARDOSO MARCHIORI² DANIEL LENA MARCHIORI NETO
}

\section{RESUMO}

No presente artigo se divulga em língua portuguesa, pela primeira vez, um texto inédito de Friedrich Sellow sobre a colheita e o preparo da erva-mate nas cercanias da antiga Missão de Santo Ângelo, no atual estado do Rio Grande do Sul, extraído de um relatório por ele enviado em 1826 ao Barão de Altenstein.

Palavras-chave: Altenstein, Erva-mate, Friedrich Sellow, Rio Grande do Sul, Sellow.

\section{ABSTRACT}

[Unpublished texts by Friedrich Sellow. 2 - Notes on harvesting and processing of yerba mate]. The text of Friedrich Sellow, extracted from a report sent by him to the Baron of Altenstein in 1826, regarding to the harvest and processing of yerba mate close to the ancient Santo Angelo Mission, in the actual State of Rio Grande do Sul (Brazil), is published here for the first time.

Kew words: Baron of Altenstein, Friedrich Sellow, Rio Grande do Sul State, Sellow, yerba mate.

\section{INTRODUÇÃO}

O relatório de Friedrich Sellow do qual se extraiu o texto do presente artigo apresenta grande interesse histórico para o Rio Grande do Sul e foi enviado de Porto Alegre ao Barão de Altenstein $^{4}$ em 12-10-1826. O manuscrito, conservado no acervo do Museu de Zoologia de Berlim, é documento de difícil acesso e quase desconhecido em nosso meio, tendo-se dele publicado em língua portuguesa, até o momento, apenas o trecho relativo à viagem do naturalista da atual fronteira com o Uruguai à região das Missões ${ }^{5}$.

1 Recebido em 10-2-2016 e aceito para publicação em 07-4-2016.

2 Engenheiro Florestal, Dr. Professor Titular do Departamento de Ciências Florestais, Centro de Ciências Rurais, Universidade Federal de Santa Maria. Bolsista de Produtividade em Pesquisa (CNPq - Brasil). marchiori@pq.cnpq.br

3 Professor, Dr. Universidade Federal do Rio Grande. danielmarchiorineto@gmail.com

4 Karl Sigmund Franz Freiherr von Stein zum Altenstein (1770-1840). Barão, político e primeiro ministro da Cultura da Prússia, responsável por importante reforma de seu sistema educacional. Foi por sua intermediação, principalmente, que Friedrich Sellow recebeu o indispensável apoio financeiro para suas excursões pelo interior do Brasil e Província Cisplatina (atual Uruguai), motivo pelo qual o naturalista lhe enviava relatórios periódicos. É de um destes, precisamente, que se extraíram os fragmentos ora publicados.
Os fragmentos que ora vem a público relatam a visita do naturalista a um erval nas cercanias da antiga missão jesuítica de Santo Ângelo, no noroeste do Rio Grande do Sul. Por sua antiguidade, trata-se de um dos relatos pioneiros sobre esta importante atividade econômica, motivo suficiente para justificar a presente publicação.

\section{MATERIAL EXAMINADO}

O texto da presente artigo baseia-se em fragmentos da cópia microfílmica do manuscrito de Friedrich Sellow em língua alemã (e em miúda letra gótica), obtida pelo professor Darcy Closs ${ }^{6}$ no início da década de 1960 no Museu de Zoologia de Berlim, por intermédio do pesquisador Erwin Stresemann ${ }^{7}$, a qual foi repassada a

\footnotetext{
5 MARCHIORI, J.N.C.; PONTES, R.C.; MARCHIORI NETO, D.L. Textos inéditos de Friedrich Sellow. 1 Viagem às Missões Jesuíticas da província de São Pedro do Rio Grande do Sul. Balduinia, Santa Maria, n. 51, p. 12-24, 2016.

6 Graduado em Geociências (UFRGS, 1955), o gaúcho Darcy Closs realizou Pós-Graduação nas universidades alemãs de Hamburgo e Tübingen, foi professor do curso de Geologia da UFRGS, presidente da CAPES (19741979) e um dos articuladores da fundação da FAPERGS (Fundação de Amparo à Pesquisa do Estado do Rio Grande do Sul). Faleceu em 11-02-1913.

7 Ornitologista alemão (Dresden, 22-11-1889 - Berlim, 20-11-1972), pesquisador do Museu Zoológico de
} 
Abeillard Barreto ${ }^{8}$, que a incorporou ao acervo da "Bibliotheca Rio-Grandense", da cidade de Rio Grande. Na mesma biblioteca também se encontra - datilografada e em volume encadernado -, a transcrição para o português do manuscrito original, realizada pela senhora Urte Casória, bem como a correspondência entre Urte e Abeillard Barreto, pela qual se fica sabendo que o texto disponível estava incompleto, faltando o "fim" do relatório, bem como várias folhas intermediárias ${ }^{9}$. Esta é a causa das interrupções que o leitor perceberá na leitura do texto, indicada, no presente artigo, por três pontos entre parênteses, ao centro da página. Os poucos termos que a senhora Urte não conseguiu "decifrar" são indicados por reticências entre parênteses, ao longo do texto.

Os dois desenhos a lápis, constantes das Figuras 1 e 2, foram realizados por Friedrich Sellow em julho de 1826, com a indicação de "St. Angelo", e foram anteriormente publicadas em 2013, na obra "Die Erkundung Brasiliens". ${ }^{10}$

\section{TEXTO DE SELLOW}

(...) Os próprios jesuítas deixaram os índios em nível inferior e lhes sufocavam o espírito de autonomia por força de uma educação inteiramente claustral, em que era tido por dever capital a obediência cega. Assim, tanto mais facilmente deles fizeram escravos os administradores espanhóis e portugueses. Foi também assim que esqueceram os nomes das plantas e dos animais do ambiente, lembrando, apenas, dos de

Berlim, professor de Zoologia da Universidade de Berlim (1930-1961) e editor do Journal für Ornithologie.

8 Funcionário do Banco do Brasil, Abeillard Vaz Dias Barreto (Rio Grande, 20-6-1908 - Rio de Janeiro, 0311-1983) destacou-se por suas preciosas contribuições à História do Rio Grande do Sul, salientando-se a famosa "Bibliografia Sul-Riograndense", obra em dois alentados volumes.

9 Informação constante em carta da Sra. Urte Casória ao Dr. Abeillard Barreto, datada de 15-08-1962, e anexada ao volume com o texto de Friedrich Sellow, vertido ao português.

10 ZISCHLER, H.; HACKETHAL, S.; ECKERT, C. (ed.). Die Erkundung Brasiliens. Berlin: Galiani, 2013. 253 p. alguns objetos bem distintos; por isso, também nesse aspecto, não colhi de minha viagem as vantagens que esperava.

A melhor situação é a de St. Ângelo, onde se cultiva, com proveito, a cana-de-açúcar e, em suas proximidades, nas matas do Uruguai e do Ijuí, se encontravam grandes ervais, trechos de mata alta em que abunda o caá, o mate ou erva, planta que, todavia, não vive em grupos ${ }^{11}$. Para observar a preparação deste chá, de todo indispensável a muito sul-americano que o reclama sofregamente e que se toma em cuias de cucurbitácea $^{12}$, por meio de um canudo com a extremidade provida de peneira ou ralo ${ }^{13}$, visitei um dos respectivos locais.

Os empreiteiros penetram na mata em companhia de seus serviçais, levando víveres, material de caçador, bons cães de caça e, inicialmente, estudam o local das árvores que vão explorar. Decidido onde se estabelecer, eles montam um acampamento, constituído de cobertura, à guisa de telhado, na forma usual ou de pirâmide, com a borda inferior a cinco pés do solo ${ }^{14}$ e sustentada por esteios, de forma que, em caso de perigo de incêndio, possam ser facilmente descobertas e postas de lado ${ }^{15}$. Se forem muito grandes ou se houver receio de que possa chover, ainda se aplica uma cobertura de sapé.

${ }^{11}$ De fato, as árvores de erva-mate, por seu menor porte, integram o sub-bosque da Floresta Latifoliada e da Floresta Mista.

12 Trata-se do porongo, fruto do porongueiro (Lagenaria siceraria (Molina) Standley). É do fruto desta Cucurbitácea que se extrai a cuia, isto é, o recipiente tradicionalmente usado para se "tomar mate". Tanto a palavra mate (mati), como porongo, provém do quíchua, a língua do império inca. Com relação a mati, o termo era utilizado, originalmente, para designar o recipiente, e não à bebida nele tomada, correspondendo à "cuia", palavra que, por sua vez, é usual tanto tupi como no guarani (cuya, kui'aua) e no português brasileiro.

13 Trata-se da "bomba", em português, ou "bombilla", em espanhol, objeto feito de metal, mormente de prata. Para sorver o mate, os índios valiam-se do tacuapí, canudo feito a partir do colmo de Poáceas do gênero Merostachys Spreng.

${ }^{14} \mathrm{O}$ valor referido corresponde a $1,524 \mathrm{~m}$.

${ }^{15}$ Ver Figura 1. 


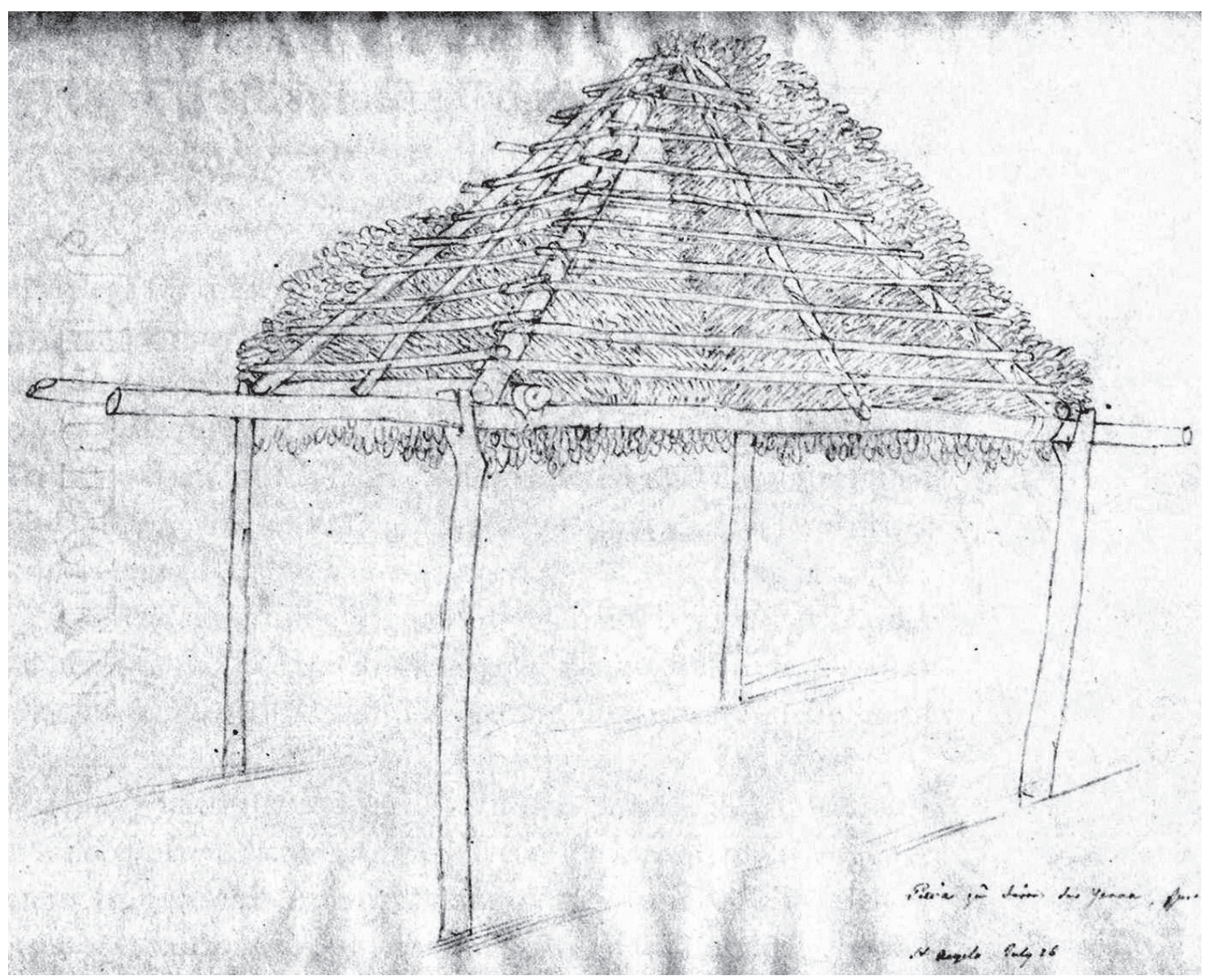

FIGURA 1 - Construção para secar a erva-mate, já meio coberta; desenho a lápis de Friedrich Sellow, julho de 1826. De: Zischler et al., 2013. Op. cit, p. 143. 


\section{(...)}

(...) aos dois, a cata da erva; um deles sobe na árvore por meio de um anel de corda em que enfia os pés. ${ }^{16} \mathrm{O}$ tronco chega a quarenta pés de altura e dois de diâmetro. ${ }^{17}$ Esse homem em seguida corta os galhos, que não devem ser muito grandes para facilitar seu manejo no fogo; o outro, enquanto isso, junta lenha para a fogueira e a acende. Os galhos derrubados são sumariamente expostos ao calor da fogueira, constantemente revirados a mão, com o que, aos estalos, sai o ar contido nas folhas pela parte inferior, que parece esburacada feito peneira. Sem essa redução das folhas, elas ficariam pretas na secagem ulterior. ${ }^{18}$ Depois daquele chamusco, os galhos são depenados em pedacinhos do tamanho de uma pena de escrever e estes enfardados em molhos de cerca de três arrobas. Cada ervateiro tem de preparar, diariamente, um desses fardos. São eles colocados sobre os varais, debaixo das coberturas preparadas, varais convenientemente interdistantes, com a haste das folhas para baixo, sendo em seguida submetidas ao calor. Para isso, acende-se uma fogueira embaixo, com lenha que desprenda cheiro balsâmico como acontece (...), de preferência variedade da (...); sempre que surjam labaredas, abafa-se com água. Logo que as folhas estejam devidamente secas, espalham-se sobre couros de boi, ou mesmo sobre uma área de chão batido e moem-se com bordões de madeira troncocônicos; por fim, ensaca-se, comprime-se, em sacos de couro cru de boi ${ }^{19}$, com capacidade de três arrobas. No preparo da erva para seu próprio uso, os índios a colocam sobre estrados de varas horizontais e por baixo aplicam somente tições, com o que evitam o sabor de fumaça, que o processo supra-referido acarreta e que só ao cabo de anos de dissipa. A árvore floresce em dezembro, frutifica em junho; o fruto é (...).

${ }^{16}$ Ainda hoje se usa essa técnica para escalar árvores.

${ }^{17}$ Os valores indicados correspondem a $12,19 \mathrm{~m}$ de altura e $60,96 \mathrm{~cm}$ de diâmetro.

${ }^{18}$ De fato: as exsicatas de erva-mate tem folhas muito escuras, se forem secas como as demais plantas.

${ }^{19}$ Ditas "bruacas", no Brasil.
A quadra mais conveniente para a colheita vai de janeiro a julho e pode ser repetida de três em três anos. Os jesuítas plantavam ervais em torno de suas missões; na de S. Luís, ainda em 1797, aí colheram três mil arrobas de erva. Desde que os administradores não exigiam mais a capinação nos ervais (...).

\section{DISCUSSÃO}

O texto de Friedrich Sellow descreve as técnicas tradicionais usadas na colheita e preparo da erva-mate, ítem fundamental para a economia do Paraguai, Argentina e sul do Brasil no século dezenove, sem destoar, em suas linhas gerais, do descrito por Felix de Azara e Auguste de Saint-Hilaire, entre outros cronistas do passado regional.

Em sua "Descrição e História do Paraguai", Azara informa que

"Para beneficiar la yerba chamuscan las hojas, pasando la misma rama por la llama. Despues la tuestan, y últimamente la desmenuzan hasta cierto punto, poniéndola en un depósito, por que recien hecha no tiene buen gusto. Para usarla poner un puñadito en una calabacita que llaman mate con agua caliente, $\mathrm{y}$ al instante chupan por un cañutillo ó bombilla que tiene en el inferior agujeros para dar paso al agua deteniendo la yerba. $(,,$,$) . Los padres jesuitas plantaron estos$ árboles en sus Misiones y beneficiaban la yerba con toda comodidad. Separaban ademas las puntitas de los palos, desmenuzaban más las hojas y llamaban a esta yerba Caá miri: mas nada de esto influye en la calidad, sino el que esté bien chamuscada, tostada y cojida en sazon no impregnada de humedad. Asi sin consideracion á quitar palitos ni á lo menudo, dividen la yerba en fuerte, y electa ó suave." 20

Sobre o mesmo tema, Auguste de SaintHilaire informa, em sua "Viagem a Curitiba e Província de Santa Catarina", que a "antiga

\footnotetext{
${ }^{20}$ AZARA, F. de. Descripcion é Historia del Paraguay y del Rio de la Plata. Madrid: Imprenta de Sanchiz, 1847. v. 1, p. 69-70.
} 


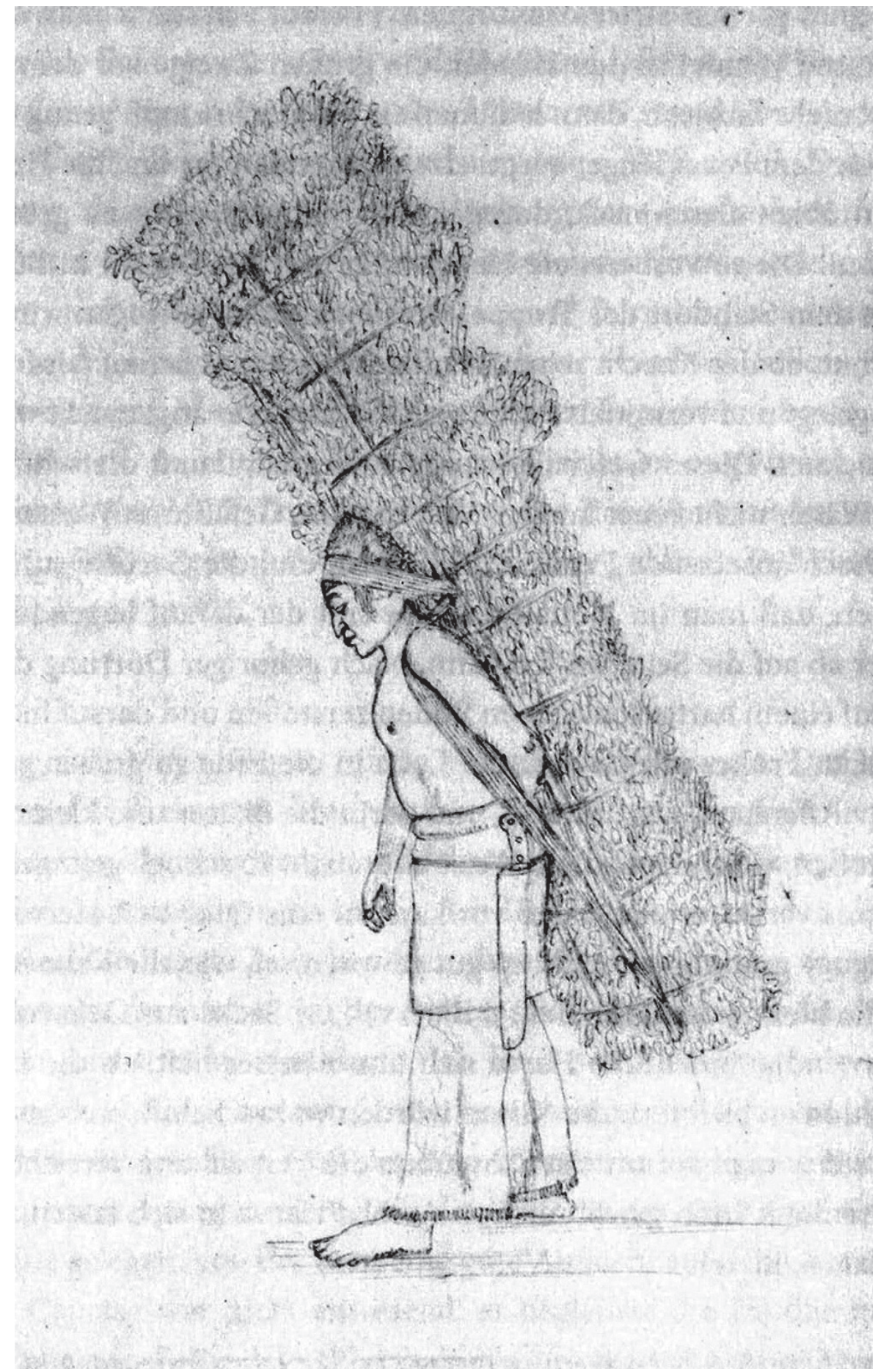

FIGURA 2 - Como os índios de Santo Ângelo transportam a erva-mate colhida na floresta; desenho a lápis de Friedrich Sellow, julho de 1826. De: Zischler et al., 2013. Op. cit, p. 142. 
maneira" de fabricação era diferente da usada no "Paraguai em vários pontos", não sendo dada "nenhuma atenção à época do ano em que se cortavam os galhos da árvore", não se usava "fogo de lenha verde" e, também, não "se construíam barbaquás", mas, "unicamente", "jiraus de cerca de um metro de altura, sobre os quais eram colocadas as folhas da erva-mate". Finalmente, a "madeira dos ramos não era aproveitada", sendo que, segundo os "hispano-americanos", é ela que "dá mais sabor à bebida". ${ }^{21} \mathrm{O}$ botânico conheceu o processo de fabricação na região da "Borda do Campo", a leste de Curitiba, quando já se encaminhava para descer a Serra do Mar, rumo a Antonina e Paranaguá, e informa que o mate ali produzido, apesar de ser "feito com muito menos cuidado" do que no Paraguai, tendia a melhorar. porque se começava a adotar o processo usual naquele país. $\mathrm{O}$ francês registra a informação de um "paraguaio", por ele conhecido na região, de que o mate deve ser colhido de "março até agosto" para ficar "bom", visto que a "diminuição do calor retarda o movimento da seiva" nesta época. ${ }^{22}$ Na sequência, ele descreve a estrutura e manuseio da erva no "barbaquá", salientando a importância do uso de lenha verde como fonte de calor.

Posterior a Sellow, visto que a obra SaintHilaire teve sua primeira edição em 1851, resta salientar, em favor do naturalista alemão, que seu texto procede de um relatório enviado para justificar recursos recebidos - e não de um livro - motivo pelo qual se explica a ausência de maiores reflexões, até mesmo pela premência de tempo e a indisponibilidade de qualquer apoio bibliográfico no momento de sua escritura. $\mathrm{O}$ mesmo se pode dizer do relato de Azara, restando acrescentar que a obra foi originalmente publicada em 1847, após a morte do autor, e que, a esse respeito, Abeillard Barreto (1973)

${ }^{21}$ SAINT-HILAIRE, A. de. Viagem a Curitiba e Província de Santa Catarina. Belo Horizonte: Ed. Itatiaia; São Paulo: Ed. da Universidade de São Paulo, 1978. p. 89.

22 SAINT-HILAIRE, A. de, 1978. Op. cit., p. 88. pondera que o conjunto do texto "demonstra melhoria gradativa" em relação ao manuscrito do autor, de 1793.

A respeito da Figura 2, além dos traços nitidamente indígenas do carregador, cabe salientar que a imagem, atemporal, serve, à perfeição, para ilustrar uma antiga referência de Antônio Ruiz de Montoya sobre o trabalho sobrehumano dos índios no início do século dezessete, forçados a transportar cargas de "cinco a seis arrobas", peso muito superior ao de seu próprio corpo, e por " 10,15 e 20 ou mais léguas". A esse respeito, o jesuíta indaga-se sobre "quantos índios não morreram" recostados em suas "cargas" e manifesta o "horror" pelo fato do "espanhol" sentir mais pela falta de quem lhe transporte a carga do que, propriamente, pela "morte do pobre índio". 23

\section{REFERÊNCIAS BIBLIOGRÁFICAS}

AZARA, F. de. Descripcion é Historia del Paraguay $y$ del Rio de la Plata. Madrid: Imprenta de Sanchiz, 1847. v. 1.446 p.

BARRETO, A. Bibliografia Sul-Riograndense. A contribuição portuguesa e estrangeira para o conhecimento e a integração do Rio Grande do Sul. Rio de Janeiro: Conselho Federal de Cultura, 1976. v. 1,736 p. v. 2, p. $737-1556$.

MARCHIORI, J.N.C.; PONTES, R.C.; MARCHIORI NETO, D.L. Textos inéditos de Friedrich Sellow. 1 - Viagem às Missões Jesuíticas da Província de São Pedro do Rio Grande do Sul. Balduinia, Santa Maria, n. 51, p. 12-24, 2016.

MONTOYA, A.R. de. Conquista espiritual feita pelos religiosos da Companhia de Jesus nas províncias do Paraguai, Paraná, Uruguai e Tape. Porto Alegre: Martins Livreiro, 1997. 296 p.

SAINT-HILAIRE, A. de. Viagem a Curitiba e Província de Santa Catarina. Belo Horizonte: Ed. Itatiaia; São Paulo: Ed. da Universidade de São Paulo, 1978. 209 p.

ZISCHLER, H.; HACKETHAL, S.; ECKERT, C. (ed.). Die Erkundung Brasiliens. Berlin: Galiani, 2013. $253 \mathrm{p}$.

\footnotetext{
${ }^{23}$ MONTOYA, A.R. de. Conquista espiritual feita pelos religiosos da Companhia de Jesus nas províncias do Paraguai, Paraná, Uruguai e Tape. Porto Alegre: Martins Livreiro, 1997. p. 42.
} 